\title{
Vape Till Your Nose Bleed
}

AZLIANA AZIZ, ${ }^{1}$ NORASNIEDA MD SHUKRI, ${ }^{1}$ RAMIZA RAMZA RAMLI $^{1}$

\begin{abstract}
:
Epistaxis although is a common presentation that seldom require surgical intervention, it is still consider as an emergency. We report a case of 26 years old gentleman with atraumatic intractable anterior epistaxis after recent history of vaping. Purpose of this case report is to highlight the flow of management of anterior epistaxis. We provide a literature review for the sequence of actions for the management of anterior epistaxis and also a discussion on association between vaping habit and epistaxis.
\end{abstract}

Key words: Epistaxis, Vape, Nose bleed.

\section{Introduction:}

Epistaxis is one of common referral seen by Otolaryngologist. Survey data suggested that about $60 \%{ }^{1}$ of adult have experienced an episode of epistaxis in their lifetime. Most epistaxis resolved spontaneously. About $6 \%$ have sought medical attention. There is subset of patient with intractable epistaxis that fail conservative treatment and most commonly occur in the posterior part of nasal airway. . The differential diagnosis include hereditary hemorrhagic telangiectasia (Osler-Weber-Rendu disease), blood dyscrasia and secondary to severe asymptomatic hypertension. In this case study, we are proposing that there is an association between vaping and epistaxis.

\section{Case report:}

A 26 years old male, with no known underlying illness has been referred to our attention by the casualty doctor for bilateral epistaxis. The epistaxis, about one small towel fully soaked, started suddenly in the evening and stopped spontaneously. He had another episode of epistaxis the next morning after waking up from bed, which also stopped spontaneously. Later, he had another episode of epistaxis that did not stop spontaneously at home, therefore prompting him to seek further treatment at the emergency department.

He denied history of trauma or any recent upper respiratory tract infection. He has no symptoms of allergic rhinitis and also no previous history of epistaxis. Patient admitted to use to smoke about 10 cigarettes per day but since stopped smoking and replacing it with vaping which he started about 1 month ago. Within that period of 1 month, he vape regularly and had tried variety of different flavoured type.

On examination, the left nostril was seen bleeding actively while the right nostril oozed blood. There were no obvious polyps or mass seen in the nose. Blood pressure was

1. Universiti Sains Malaysia, Malaysia

Corresponding author: Azliana Aziz, Universitiy Sains Malaysia, Malaysia.Email: az_aziz@usm.my documented at $140 / 80 \mathrm{mmHg}$ with pulse of $82 \mathrm{bpm}$ and temperature of 37 degree Celcius. Both nostrils were packed with merocel size $10 \mathrm{~mm}$ and the patient was admitted to the ward for observation.

In the ward, intravenous Augmentin was started and regular bolster charting was done. The epistaxis persisted after nasal pack was removed 48 hours later which during the time there were no evidence of bleeding evidence by the bolster chart. In view of the persistence epistaxis, he was scheduled for examination under general anaesthesia for proper assessment to find the cause of bleeding.

Intraoperatively, generalised 'spider nevi' appearances on the mucosal surfaces seen especially over medial surface of the inferior turbinate, anterior surface of middle turbinate and septum in both nostrils. The 'spider nevi', telangiectasia like vessel easily bled and looked very fragile. Each involved area were diathermised using bipolar bilaterally at best to addressed the more prominent of the 'spider nevi' lesion. Nasopore nasal packs were inserted in both nostrils right after chloramphenicol ointment was applied over bilateral nasal cavity.

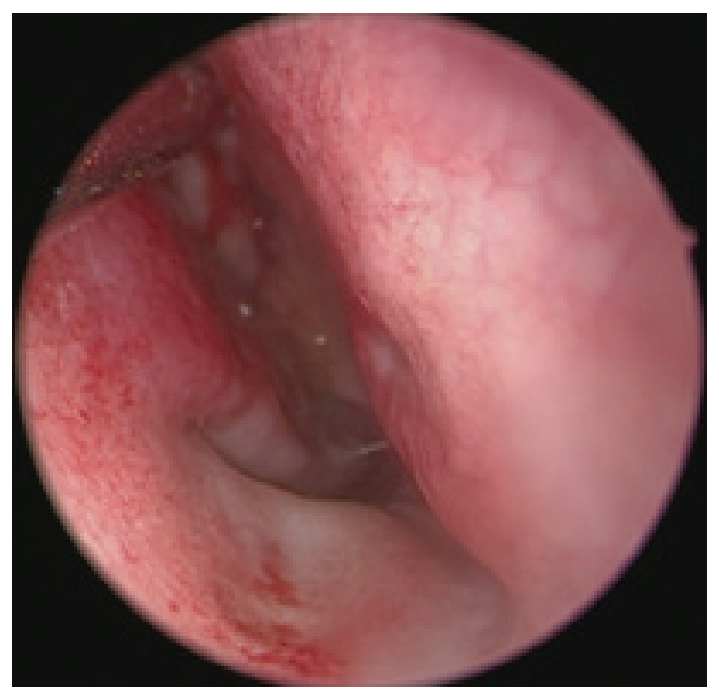

Fig.-1: Endoscopic image of the right nostril 


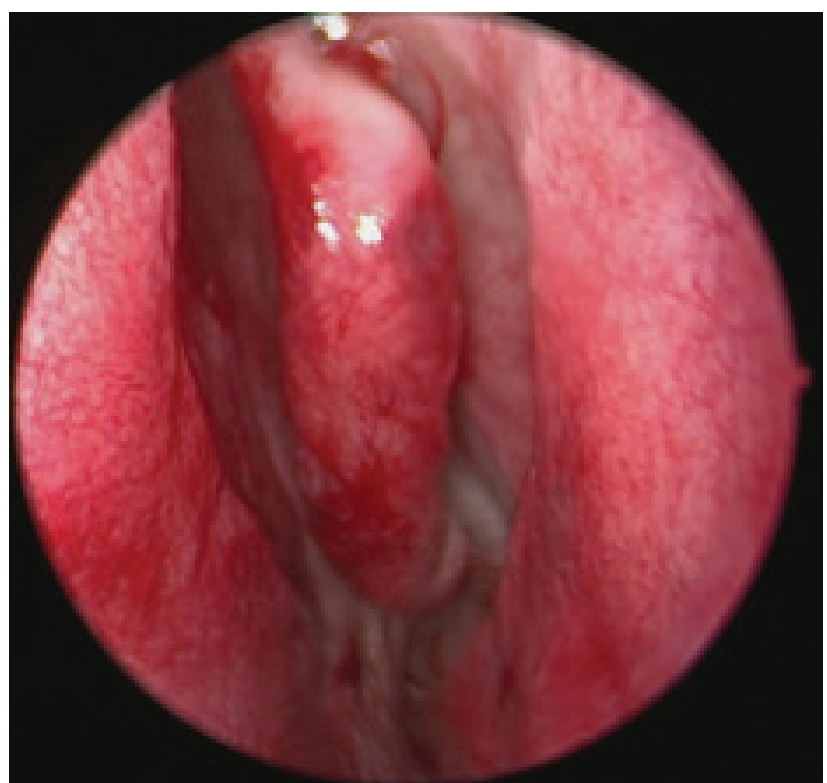

Fig.-2: Endoscopic image of left nostril with middle turbinate in the middle

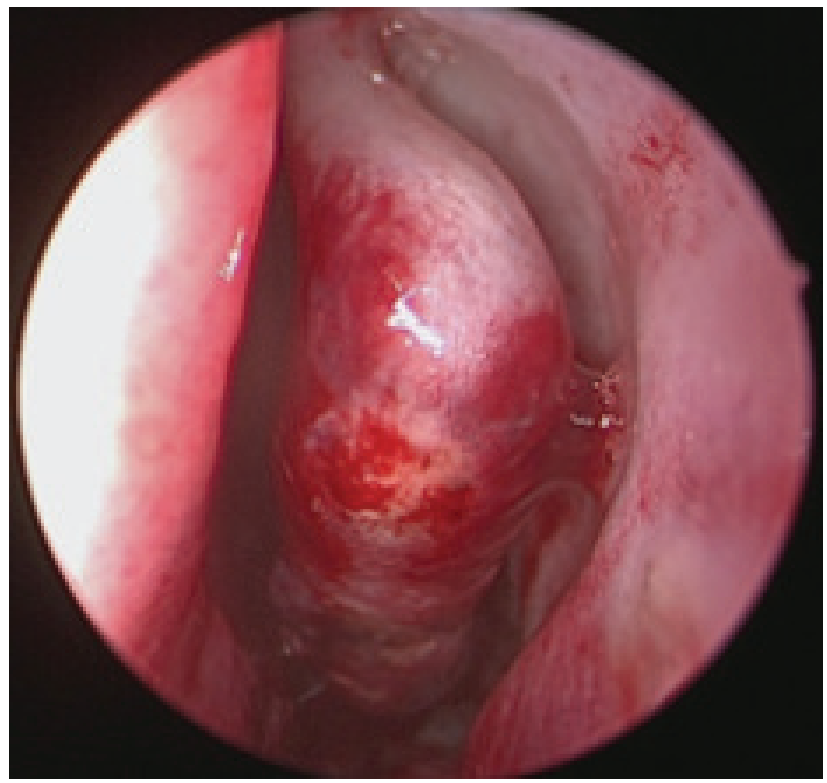

Fig.-3: Closer look of the left middle turbinate

Postoperatively, no epistaxis documented.A week follow up, patientdid not complain of any episode of epistaxis and the endoscopic examination shows crusting over the diathermised area with no evidence of bleeding. The histopathology result from the affected area came back with no significant pathology. After 6 months follow up, patient had no episode of epistaxis and he climed that he has stopped vapping and smoking.

\section{Discussion:}

Epistaxis is a common presentation that requires Otorhinolaryngology referral, affecting about 60 percent of the population, ${ }^{1}$ which can lead to hospital admission and seldom require surgical intervention. It is estimated about $6 \%$ in minority of patient that the bleeding continues and requires medical attention.For most patients, epistaxis resolved spontaneously particularly in the anterior epistaxis. Local pressure or nasal packing is sufficient for most patients. $^{2}$

One of the common causes of epistaxis is the spontaneous idiopathic atraumatic epistaxis. It has a bimodal age distribution with cases before age 10 and between 45 and 65 years old. ${ }^{3}$ Survey done by Kotecha et al in England and Wales identified average number of 10.2 patient were admitted with epistaxis over period of 3 months per consultant and $70 \%$ among them were aged 60 years or over. ${ }^{4}$ Hospital admission increases progressively with age.

Patients who fail conservative measures are said to have intractable epistaxis. This is common in patient with posterior epistaxis as it can be difficult to manage and require more intensive level of care ${ }^{2}$.Arteriosclerosis and hypertension are most common risk factors for epistaxis in older patients with posterior bleeds. However, in this case patient has no known medical illness and his intractable epistaxis occured at the anterior part of the nasal airway.

Other spectrums of differential diagnosis in epistaxis can be from local factors, systemic disorders, environmental factors, benign to malignant neoplasm and genetic disorder. Examples include trauma, foreign body, cold and dry air, carcinomas as well as Osler-Weber-Rendu disease. In tropical country, epistaxis is a known complication of thrombocytopenia due to dengue fever.Therefore, it is crucial to identify the causes of epistaxis in order to manage the condition appropriately.

One of the direct treatment of visibly localised traumatic epistaxis over the anterior part of the nasal airway is having to stopped the bleeding area under direct vision. This can be achieved by cauterizing it using silver nitrate or electrocautery. About 90 to 95 percent anterior epistaxis stopped with nasal packing. 5,6

While on nasal packing, it is alsoadvisable to start prophylactic antibiotics especially those with diabetes, advanced age or immunosuppressed. An antibiotics with staphylococcal coverage such as amoxicillin-clavulanate or second generation cephalosporin was recommended. ${ }^{7}$

In the event of intractable epistaxis after conservative measures and nasal packing, surgical treatment is performed. 
Thesemay include ligation of the sphenopalatine or anterior ethmoidal artery. Angiographic embolization is becoming more common and the result is about 90 percent successful rate. ${ }^{8,9}$ However, there are 4 percent rate of severe complications like stroke and blindness with embolization. ${ }^{10}$

In this case study, we were unable to detect any obvious causes that may lead this patient to have an anterior nasal airway spontaneous intractable epistaxis episodes besides his prior engagement in vaping habit. There is not yet case study published reporting the association between vaping habit and intractable epistaxis.

Vape or electronic cigarette contains propylene glycol or glycerol also called propane-1,2-diol, is an organic compound with the chemical formula $\mathrm{C}_{3} \mathrm{H}_{8} \mathrm{O}_{2}$ as one of the major ingredient apart from liquid nicotine and flavouring used in the electronic cigarettes. Very little is known to human about the effect of heated and aerosolized propylene glycol. It can decomposes and form propylene oxide, a probable human carcinogen at high temperature. ${ }^{11}$ Both propylene glycol and glycerol decompose to form carcinogens formaldehyde and acetaldehyde depending on the voltage of the battery used in the e-cigarette. ${ }^{12,13}$

An e-cigarette consists of a catridgec ontining a liquid, an atomizer which is a vaporization chamber with a heating element and a battery. Activation of the atomizer will heat the liquid and produces a vapor to inhale. Also in e-cigarette, a significant number of the flavour chemicals used were aldehydes, a compound class recognised as 'primary irritants' of mucosal tissue of the respiratory tract. ${ }^{14}$ The possible correlation and explaination to what may causes epistaxis when vaping in our case is that the combination of drying effect of the vapour and its irritative chemicals causes the epistaxis. Further evidence and research is much needed. Further questions can also be raised in finding out the longterm consequences of e-cigarette use which is still unknown.

\section{Conclusion:}

This is the first case study trying to associate between habit and intractable epistaxis. Intractable anterior epistaxis was observed without any other remarkable history apart from significant history of recent vaping habit. More data and study needed for the evaluation of the association between vaping or e cigarette with epistaxis.

\section{Conflict of interest: None.}

\section{References:}

1. Kucik CJ, Clenney T. Management of epistaxis. Am Fam Physician 2005;71(2):305-11.

2. Folz BJ, Kanne M, Werner JA. Current aspects in epistaxis. HNO. 2008;56(11):1157-65. doi: 10.1007/ s00106-008-1838-3.

3. Pallin DJ, ChngYM, McKay MP, et al. Epidemiology of epistaxis in US emergency departments, 1992 to 2001. Ann Emerg Med 2005; 46(1):77-81.

4. Kotecha B, Fowler S, Harkness P, et al. Management of epistaxis: a national survey. Ann R CollSurgEngl 1996;78(5):444-6.

5. Corbridge RJ, Djazaeri B, Hellier WP, et al. A prospective randomized controlled trial comparing the use of merocel nasal tampons and BIPP in the control of acute epistaxis. ClinOtolaryngol Allied Sci 1995;20(4):305-7.

6. McGlashanJA, Walsh R, Dauod A, et al. A comparative study of calcium sodium alginate (Kaltostat) and bismuth tribromophenate (Xeroform) packing in the management of epistaxis. J LaryngolOtol 1992;106(12):1067-71.

7. RejasUgena E, Trinidad Ruiz G, Alvarez Domínguez J, et al. Utility of the surgical treatment for severe epistaxis by endoscopic approach of sphenopalatine and ethmoidal arteries. ActaOtorrinolaringolEsp 2006;57:228-234.

8. Tseng EY, Narducci CA, Willing SJ, et al. Angiographic embolization for epistaxis: a review of 114 cases. Laryngoscope 1998;108:615-9.

9. Moshaver A, Harris JR, Liu R, et al. Early operative intervention versus conventional treatment in epistaxis: randomized p rospective trial. J Otolaryngol 2004; 33(3): 185-8.

10. Schlosser RJ. Clinical practice. Epistaxis. N Engl J Med 2009;360(8):784-9.

11. Laino T, Tuma C, Moor P, et al. Mechanisms of propylene glycol and triacetin pyrolysis. J PhysChem A 2012;116(18):4602-9.

12. Kosmider L, Sobczak A, Fik M, et al. Carbonyl compounds in electronic cigarette vapors: effects of nicotine solvent and battery output voltage. Nicotine Tob Res 2014;16(10):131926.

13. Jensen RP, Luo W, PankowJF, et al. Hidden formaldehyde in e-cigarette aerosols. N Engl J Med 2015;372(4):392-4.

14. William PL, James RC, Roberts SM, et al. Principles of toxicology: environmental and industrial applications. John Wiley \& Sons, 2015:346-496. 